\title{
The effect of selected metals on the central metabolic pathways in biology: A review
}

\author{
C Strydom ${ }^{1}$, C Robinson ${ }^{1}$, E Pretorius ${ }^{1 *}$, JM Whitcutt ${ }^{2}, \mathrm{~J} \mathrm{Marx}^{1}$ and MS Bornman ${ }^{3}$ \\ ${ }^{1}$ Department of Anatomy, School of Health Sciences, Faculty of Health Sciences, \\ University of Pretoria, PO Box 2034, Pretoria, 0001, South Africa \\ ${ }^{2}$ Highveld Biological Association, Sandringham, Johannesburg, South Africa \\ ${ }^{3}$ Departments of Urology, School of Medicine, Faculty of Health Sciences, University of Pretoria, South Africa
}

\begin{abstract}
In South Africa, mining and industrial activity may cause toxic substances including metals to pollute surface and groundwater resources. Furthermore, there is an increased public awareness regarding pesticides, fertilisers, agricultural products and metals that might endanger our indigenous fish populations and aquatic ecosystems. This is mainly because humans use these natural resources as food and water supplies and are therefore also exposed to products polluting these resources. Of particular concern is the exposure of bio-organisms to metal pollution, as it is known that metals act as mutagenic/genotoxic compounds, interfere with xenobiotic metabolic pathways, and may also affect glycolysis, the Krebs cycle, oxidative phosphorylation, protein amino acid metabolism as well as carbohydrate and lipid metabolism. Therefore, in this review, we discuss the two phases of the central metabolic pathways, as well as how metals affect the different enzymes and metabolic processes in these pathways. The focus is particularly on metals most frequently found in groundwater in South Africa and include cadmium $(\mathrm{Cd})$, copper $(\mathrm{Cu})$, aluminium $(\mathrm{Al})$, zinc $(\mathrm{Zn})$, lead $(\mathrm{Pb})$, arsenic $(\mathrm{As})$, iron $(\mathrm{Fe})$, manganese $(\mathrm{Mn})$ and chromium $(\mathrm{Cr})$. We conclude that metals in the environment and polluting our groundwater may have a major impact on human and animal life and that ultimately exposure to these products may be the cause of many diseases due to their effect on the central metabolic pathways.
\end{abstract}

Keywords: metals, metabolic pathways, groundwater, pollution

\section{Introduction}

There has been a general global increase in industrial activity over the past few decades, resulting in a significant application of metals in the various processes, in turn causing a great escalation of metals in the environment. Although some metals are essential to human health and may be found naturally at low concentrations in the body, these may act as toxicants when humans or animals are exposed to high concentrations, which cause wide-ranging toxicological effects in these organisms as the metals tend to accumulate in several tissues. In South Africa, mining and industrial activity may cause toxic substances including metals to pollute surface and groundwater resources. Many South Africans still do not have access to clean potable water and rely on streams, rivers, marshes and other types of wetlands for their daily water supply as one of the most limiting natural resources in South Africa is water (DWAF, 1986).

Approximately $20 \%$ (7 million people) of the South African population does not have access to an adequate supply of potable water, and half of the population (21 million) lacks basic sanitation (WRCA, 2003). Underground rocks and soils may contain arsenic, cadmium, chromium, lead, and selenium but these metals are usually not found at levels of concern. However, activities such as mining and construction can release large amounts of metals into nearby groundwater sources, which at high levels pose a health risk according to a report published by the United States Environmental Protection Agency (2006).

\footnotetext{
* To whom all correspondence should be addressed.

II: +27 12319 2533; fax: +27123192240 ;

e-mail: resia.pretorius@up.ac.za

Received 30 September 2005; accepted in revised form 30 August 2006.
}

Currently, it is difficult to find any source of water that does not carry fingerprints of human activity (United Nations Environment Programme, 2004). Acid rain and increasing numbers of synthetic organic compounds and metabolised pharmaceuticals are finding their way into surface waters in unlikely places (Huang and Xia, 2001), and identifying them by untargeted chemical analysis is prohibitively expensive. Even after chemical identification the possibility of synergism/additively remains.

Public concerns regarding pesticide, fertiliser, agricultural products and metals in recent years have escalated, particularly following major fish kills in the Mpumalanga and Eastern Cape rivers (Heath and Claassen, 1999). The impact of pollutants on specifically aquatic ecosystems is either acute (due to exposure to immediate lethal dose) or insidious/chronic (due to gradual accumulation of lethal concentrations in body tissues) Heath and Claassen (1999). Unfortunately, humans using these fish resources may therefore also be exposed to 'lethal' concentrations of these pollutants, because it is well-known that fish accumulate metals in tissue and organs when exposed to metal polluted water.

According to the WRC, currently fish are considered to be an extremely reliable component of an aquatic monitoring system, because they integrate the effect of detrimental environmental changes as consumers, which are relatively high in the aquatic food chain. In a South African study it was found that metals accumulate in different fish tissues, e.g. As, Cd, Ni, Co, $\mathrm{Mg}, \mathrm{Fe}, \mathrm{Cu}, \mathrm{Pb}$, were found in the liver; $\mathrm{Zn}, \mathrm{Al}$, and $\mathrm{Mn}$ were found in the gills; $\mathrm{Al}$ and $\mathrm{Cr}$ were found in the testes, while $\mathrm{Cd}$ and $\mathrm{Co}$ were found in the ovaries. The above-mentioned metals are frequently termed heavy metals. However, over the past few 


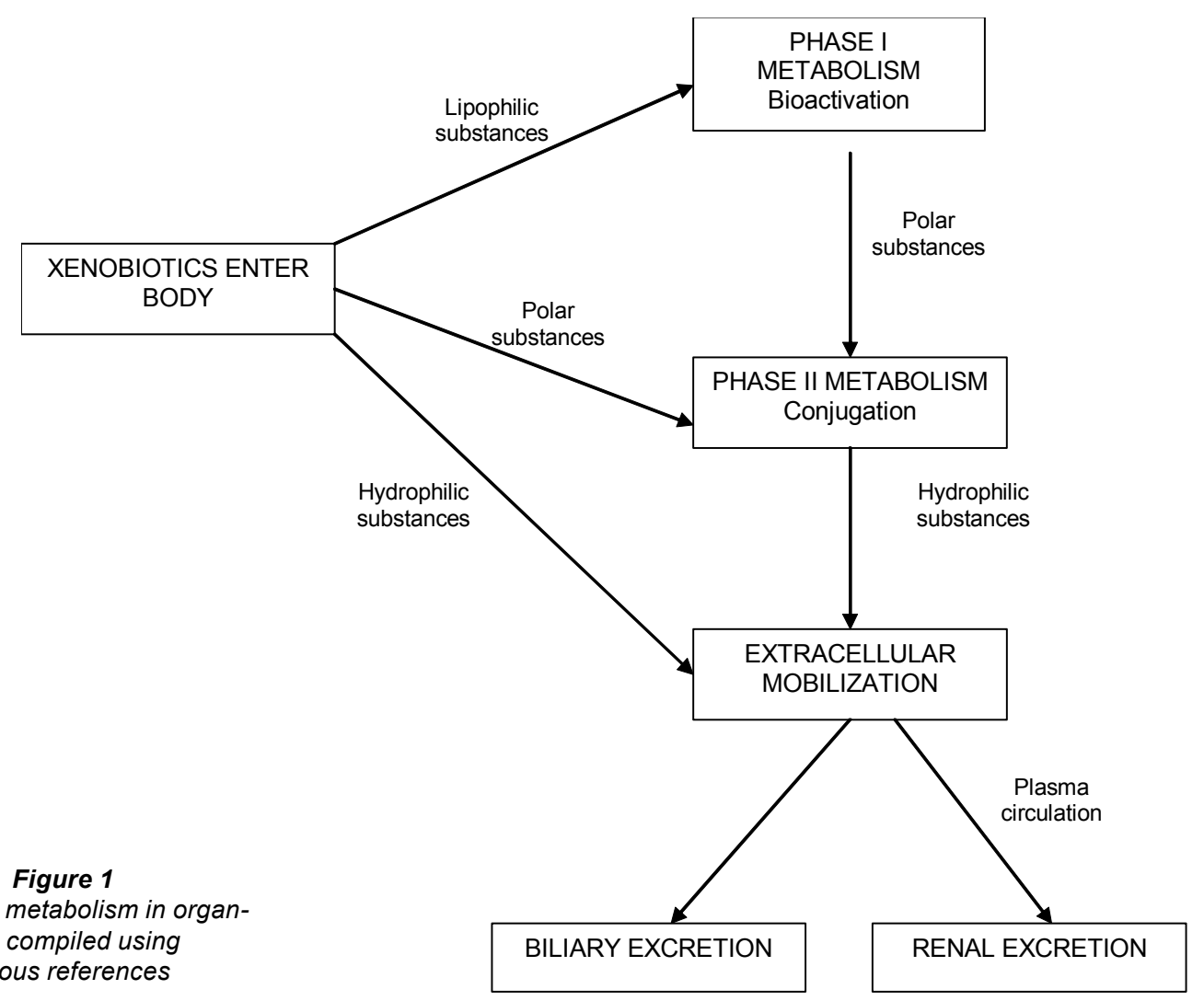

years there has been debate regarding the term 'heavy' (IUPAC, 2002; Hodson, 2004; Duffus, 2002) and in this paper we will refer to the term 'metal' and not 'heavy metal'.

These metals, usually in the ionic form cause fish mortalities, but complex metal compounds act by accumulating in the body tissues over a period of time (chronic exposure) (Ellis, 1989; Heath and Claassen, 1999). However, a compounding factor is that ecological risks from metal contaminants are difficult to document because responses differ among species, threats differ among metals, and environmental influences are complex (Luoma and Rainbow, 2005). However, it is known that metals can have the following effects on bio-organisms (Codina et al., 1994; Jannaschk et al., 1999; Almeida et al., 2001; Sanchez-Galen et al., 2001; Vernhet et al., 2001; Pouls 2002; Ohe et al., 2004):

- Act as mutagenic/genotoxic compounds

- Increased metal loads can overcome xenobiotic metabolic pathways

- Affect glycolysis, Krebs cycle, oxidative phosphorylation, protein amino acid metabolism as well as carbohydrate and lipid metabolism.

A substance that is labelled as mutagenic can induce or increase the frequency of mutation in an organism; while a genotoxic substance is able to cause harmful changes to DNA). Metals acting as mutagenic/genotoxic compounds can become the components of complex environmental mixtures that can have adverse health effects on humans and indigenous biota (Ohe et al., 2004). According to Ohe and co-workers (2004) several metals including arsenic, cadmium, chromium, nickel and lead are known to be genotoxic in vitro (Codina et al., 1994) and in vivo (Sanchez-Galan et al., 2001) Genotoxic metals, include arsenic, chromium, nickel, lead and cadmium (Ohe et al., 2004).

An increased body burden of metals may overcome the normal xenobiotic metabolism pathways (Pouls, 2002) and may influence the pathways of detoxification through Phase I and Phase II metabolic enzymes (discussed in detail later). The overload of metals may also affect oxidative metabolism such as glycolysis, Krebs cycle, oxidative phosphorylation and protein amino acid metabolism. Several metals have a high affinity for the free electron pairs of the mercapto compounds (S-H groups), occurring in enzymes, particularly those enzymes active in the metabolic pathways, and researchers have suggested that metals irreversibly inhibit several enzymes of metabolic pathways concurrently by interfering with their S-H groups (Jannaschk et al., 1999; Vernhet et al., 2001). The toxic effect of metals on the central metabolic pathways of the body is therefore becoming a major concern and more research needs to be done in order to ascertain exactly where the metals are acting on the metabolic pathways, and establish the exact physiological interferences. Furthermore, metals also produce an affect carbohydrate, protein and lipid metabolism (Almeida et al., 2001) which may additionally impact on the metabolic pathways of bio-organisms.

It is therefore clear that exposure of bio-organisms to metals can cause long-term and non-reversible effects (Cheng, 2003). Because metals in the environment may have a profound impact on the physiology and general health of the exposed organism, this review will focus on the impact of well-known and frequently occurring metals on the central metabolic pathways and how metals affect the different enzymes. According to a WRC report (Health and Claassen, 1999) the following metals are most frequently found in groundwater in South Africa and these will be reviewed: $\mathrm{Cd}$ (e.g. $\mathrm{Cd}^{2+}$ and $\mathrm{CdCl}_{2}$ ), $\mathrm{Cu}$ (e.g. $\mathrm{CuSO}_{4} \cdot 5 \mathrm{H}_{2} \mathrm{O}$ and $\mathrm{CuCl}_{2}$ ); fluoride $(\mathrm{F})$ and its interactions with metals like $\mathrm{Al}$ (e.g. fluoroaluminate $\left(3 \mathrm{mM} \mathrm{NaF}+\mathrm{AlCI}_{3}\right)$ ), $\mathrm{Fe}\left(\right.$ e.g. $\left.\mathrm{FeCl}_{2}\right), \mathrm{Zn}$ (e.g. $\mathrm{Zn}^{2+}$ and $\left.\mathrm{Zn}^{2+}\left(\mathrm{ZnSO}_{4} \cdot \mathrm{H}_{2} \mathrm{O}\right)\right)$; $\mathrm{Pb}\left(\right.$ e.g. $\left(\mathrm{Pb}^{2+} / \mathrm{Pb}(\mathrm{II})\right)$, As (e.g. $\mathrm{As}^{3+}, \mathrm{As}_{2} \mathrm{O}_{3}$ and sodium arsenite $\left.\left(\mathrm{NaAsO}_{2}\right)\right)$ Mn (e.g. $\left.\mathrm{MnCl}_{2}\right)$ and $\mathrm{Cr}\left(\right.$ e.g. $\mathrm{Cr}^{3+}$ and $\left.\mathrm{Cr}^{6+} / \mathrm{Cr}(\mathrm{VI})\right)$. 


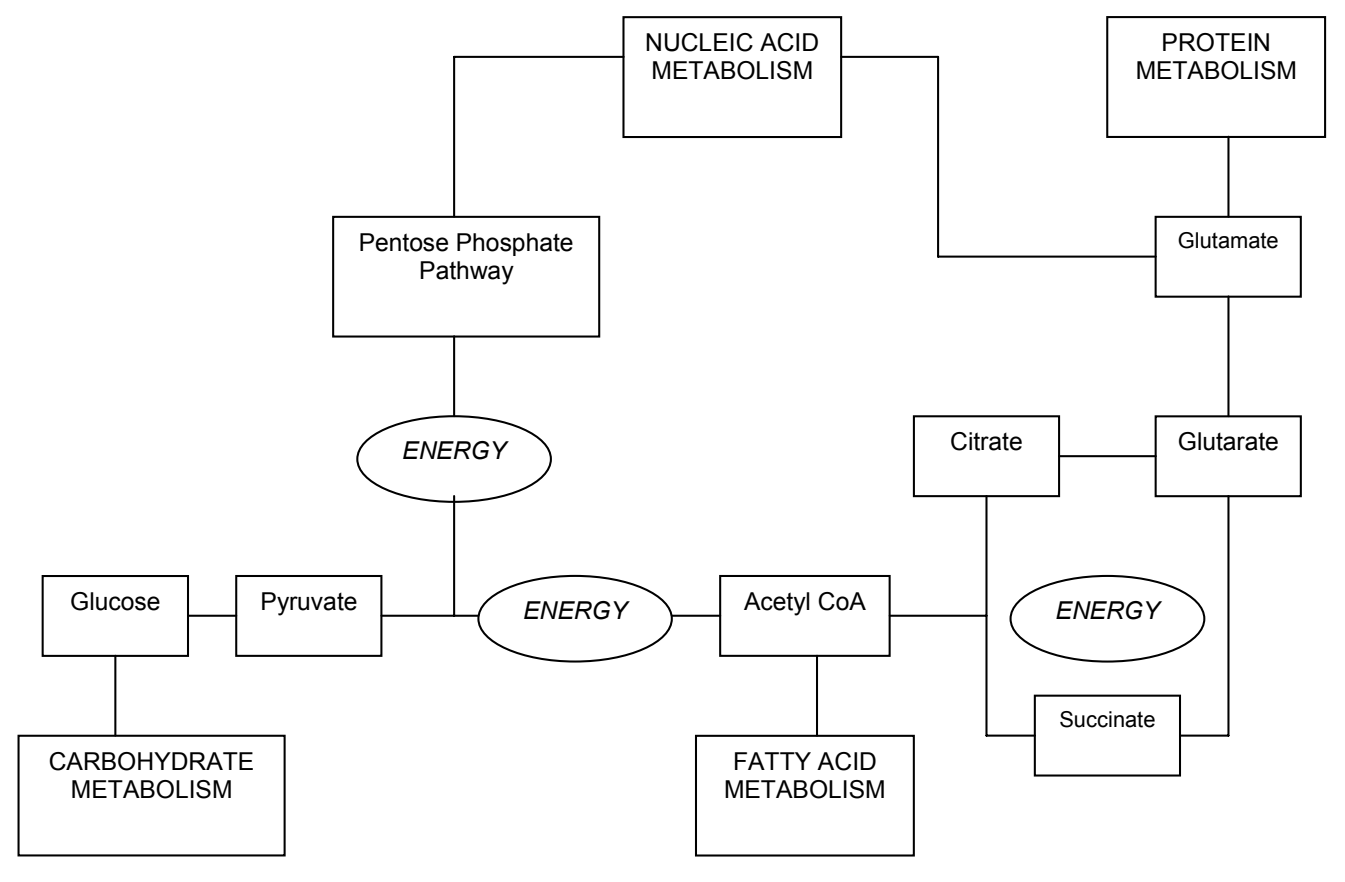

Figure 2

Simplified representation of the central metabolic pathways in the human body compiled using various references

\section{Literature review}

Metals are classified as xenobiotics which are defined as chemical substances that are foreign to the biological system. Other compounds that are also classified as xenobiotics include, e.g. drugs, environmental agents, carcinogens and insecticides that interact with the normal metabolic pathways.

After entering the body, toxins (including the metals mentioned earlier) are metabolised by a wide array of detoxifying enzymes that convert lipophilic toxins to more hydrophilic molecules (Fig. 1). The process of metabolism or detoxification comprises sequential actions of two families of enzymes: Phase I enzyme and Phase II enzyme metabolism (Xu et al., 2005) catalytic enzymes are the so-called xenobiotic metabolising enzymes (Donato and Castell, 2003), which mediate the metabolic activation and deactivation of potentially toxic agents (Schoket et al., 2001). Phase I and Phase II metabolic pathways are part of general metabolism (metabolism is defined as the sum total of all biochemical processes in an organism). The molecules of carbohydrates, fats and proteins taken up by an organism are processed in a number of different ways (Campbell, 1999). Glycolysis, the pentose phosphate pathway, the citric acid cycle and electron transport and oxidative phosphorylation all take place in the central metabolic pathway. Figure 2 is a simplified view of the central metabolic pathways and demonstrates how the pathways are linked together.

Xenobiotics are usually very lipophilic and need to undergo biotransformation to be converted into more water-soluble compounds to allow them to be excreted from the body in the urine (Klaassen, 2001). Biotransformation is critical both to the elimination of xenobiotics like metals and to the processing and recycling of endogenous compounds (Donato and Castell, 2003). The most common biotransformation site in the human body is the liver; however, biotransformation also takes place in other tissues, but to a lesser extent (Klaassen, 2001).

Phase I of the central metabolic pathway is the biotransformation phase that increases the hydrophilicity of xenobiotics by adding new functional groups to the compound or by transforming the existing functional groups. Reactions from this phase comprise oxidation, reduction and hydrolysis reactions (Donato and Castell, 2003; Klaassen, 2001; Lyer and Sinz, 1999; Livingstone, 1998).

Enzymes from Phase I are composed of the cytochrome P450 family of enzymes, (which are located within the smooth endoplasmic reticulum and microsomes in the liver), and transmembrane proteins. These enzymes are responsible for catalyzing lipophilic reactions, which functionalise compounds through oxidation, reduction and hydroxylation and require NADPH and NADP as cofactors. The cytochrome P450 gene super family, together with the flavin mono-oxygenases, plays a dominant role in Phase I reactions in the metabolism of many drugs and xenobiotics. Various forms of cytochrome P450s are present in humans and cytochrome P450 3A4 is the major form found in the human liver. Cytochrome P450 3A4 plays an important role in detoxification of drugs, carcinogens, pesticides and many endogenous compounds such as steroids (Donato and Castell 2003; Mehmood et al., 1996).

Phase I enzymes are also capable of directly neutralising some of the toxins that enter the body, but many others are converted to intermediate forms which are then processed by Phase II enzymes. These intermediate forms are often much more toxic than the initial compounds and, therefore, if the Phase II detoxification systems are not functioning properly, these intermediates can be cytotoxic (Donato and Castell, 2003).

Phase II is the conjugation phase that either establishes a covalent linkage between the xenobiotic, or links one of its metabolites to a water-soluble, endogenous compound, e.g., glutathione (Klaassen, 2001). However, in order for Phase II metabolism to occur, the substrate must have a 'functional handle' on its particle to support the conjugation reaction, and the Phase II substrates may be parent compounds or metabolites of Phase 1 reactions. Phase II reactions also further enhance the polarity of the metabolites (Iyer and Sinz, 1999). This allows for elimination from the body via the urine. 


\begin{tabular}{|c|c|}
\hline \multicolumn{2}{|c|}{$\begin{array}{l}\text { TABLE } 1 \\
\text { The protective functions of inducible Phase } 2 \text { proteins (compiled from Talalay and Fahey, 2001) }\end{array}$} \\
\hline Inducible Phase 2 proteins & Protective mechanism \\
\hline - Glutathione $\mathrm{S}$ transferases $(\mu \alpha \dot{\alpha} \pi)$ & $\begin{array}{l}\text { - } \quad \text { Conjugate with glutathione (GSH) } \\
\text { - } \quad \text { Reduce alkyl, lipid and DNA base hydroperoxides }\end{array}$ \\
\hline - UDP- glucuronosyltransferases & - Conjugate with glucuronic acid \\
\hline $\begin{array}{ll}\text { - } & \text { NAD(P)H:Quinone } \\
\text { Oxidoreductase } \\
\text { - } \\
\text { (QR, NQO1) }\end{array}$ & $\begin{array}{l}\text { - Reduce quinones to hydroquinones } \\
\text { - Prevent oxidative cycling } \\
\text { - Regenerate coenzyme Q, Vitamin E }\end{array}$ \\
\hline - Epoxide hydrolases & - $\quad$ Hydrolyze epoxides \\
\hline - Dihydrodiol dehydrogenase & - Converts dihydrodiols to catechols \\
\hline - $\gamma$-Glutamylcysteine synthetase & - Increases GSH levels \\
\hline - Heme oxygenase 1 & - $\quad$ Generates anti-oxidants ( bilirubin, $\mathrm{CO}$ ) \\
\hline - Ferritin (heavy GHT chains) & - Sequesters free ferrous iron \\
\hline - Aflatoxin B1 aldehyde reductase & - Reduces reactive metabolite \\
\hline - Leukotriene B4 dehydrogenase & - Depletes leukotriene B4 and reduces inflammation \\
\hline - Catalase & - $\quad$ Reduces hydrogen peroxide levels \\
\hline - Manganese super-oxide dismutase & - Reduces super-oxide levels \\
\hline Glutathione conjugate efflux pumps & Expel GSH conjugates from cells \\
\hline
\end{tabular}

Enzymes active in Phase II are located in the cytoplasm and endoplasmic reticulum and promote conjugations of Phase I products with endogenous ligands such as glutathione (GSH), glucuronic and amino acids (Talalay, 2000) to inactivate the drug by making it more water-soluble (polar), which is important for elimination and excretion.

The function of Phase II enzymes can be defined by the following properties (Talalay, 2000):

- Coordinate induction by many types of inducers that also induce classical Phase 2 enzymes such as glutathione-Stransferase (GSTs)

- Regulation by mechanisms that are very similar and may involve common promoter elements (e.g. Antioxidant Responsive Element, ARE)

- Catalysis of a wide variety of reactions that serve to protect cells against toxicities of electrophiles and reactive oxygen species by converting them to less toxic products

- The induction of Phase 2 enzymes is effective and sufficient to accomplish cellular protection against toxic and neoplastic effects of electrophiles and reactive oxygen species (ROS) The description of Phase II proteins should, however, not be limited to enzymes that promote conjugations with endogenous ligands such as glutathione and glucuronic acid, but should include a number of proteins that are induced by the same types of chemo-protective inducers.

These proteins as well as their protective mechanisms are listed in Table 1.

As mentioned in the previous paragraphs, metals interact with both phases of the central metabolic pathways. Therefore, a few of the well-known metals will now be reviewed and the influence on the two phases and oxidative metabolism indicated. Figure 3 shows where each of these metals influences the different areas in the metabolic pathway.

\section{Metals and their role in the metabolic pathways}

\section{Cadmium}

Cadmium is a non-essential metal (Baker et al., 2002), and a non-degradable cumulative pollutant that is highly toxic, widely distributed in the environment and can adversely affect organisms at relatively low concentrations. Its concentrations can be traced in soil, water, food and tobacco smoke is also one of the most common sources of cadmium (Moore, 2004; Soengas et al., 1996). For these reasons it is often used in environmental and ecotoxicological studies (Almeida et al., 2001; Soengas et al., 1996). Cadmium is also widely used in steel industry alloys, in planting, in batteries and in pigments used in paints, inks, plastic, and enamels (Timbrell, 2000). Because of its long biological half-life of 15 to 30 years, cadmium excretion is nearly impossible and it will, therefore, accumulate in blood, kidneys, liver and reproductive organs making it a very toxic metal. Cadmium and its ionic forms $\left(\mathrm{Cd}^{2+}\right.$ and $\mathrm{CdCl}_{2}$ ) have become a serious problem in human health (Baker et al., 2003; Henson and Chedrese, 2004) and have also been found to inhibit drug metabolism in rats. Furthermore, it is not an essential trace element, thus once it is incorporated by the organism it does not have a metabolic pathway and net accumulation occurs. An important fact is also that cadmium may interact with other metals such as iron, calcium, copper and zinc (Khan et al., 1991) and influence the enzyme activities of metabolic pathways (these interactions will be discussed later).

Furthermore, the ionic form of cadmium, $\mathrm{Cd}^{2+}$ induces haem oxygenase, which causes a decline in cytochrome P450 levels (Moore, 2004). Cadmium was also shown to be a specific inhibitor of different isoforms of cytochrome P450 such as CYP2E and CYP3A and human kidney CYP4A11 and Cd exposure also induces metallothionein. In a cultured transformed human cell line, low concentration $\mathrm{Cd}$ exposure induced specific cytochrome P450 enzymes, such as CYP1A1 and CYP2C9 (Moore, 2004). Cadmium also influences the enzymatic effects of the threonine pathway in Escherichia coli, and even at low concentrations, it can significantly decrease or even block the pathway at several steps (Chassagnole et al., 2003).

Almeida and co-workers (2001) conducted a study to evaluate the influence of exposure to sub-lethal concentrations of $\mathrm{CdCl}_{2}$ on the metabolic pathways of the freshwater fish Oreochromis niloticus. Their results indicated adverse effects such 
as slower growth, the inhibition of calcium uptake in the gills and altered liver function. The total protein concentrations of the white muscle and liver were significantly decreased. Results also indicated a decrease in the aspartate transaminase (AST) activities in the red and white muscles of the $\mathrm{CdCl}_{2}$-exposed fish (Almeida et al., 2001). These findings correlate with the results of Vaglio and Landriscina (1999) who also reported a reduction in the AST and alanine transaminase (ALT) activities in the tissues of $\mathrm{CdCl}_{2}$ - exposed fish. The exposure of fish to cadmium also caused a decrease in phosphofructokinase (PFK) activities in the fish muscle and liver, which shows that the glycolytic capabilities in these tissues were diminished - PFK is an enzyme of glycolysis. The toxic effects of $\mathrm{CdCl}_{2}$ exposure could be accredited to the inhibition of energy-yielding processes and the metabolic changes brought on by the $\mathrm{CdCl}_{2}$ exposure were similar to those seen in starvation (Almeida et al., 2001).

Soengas and co-workers in 1996 studied the effects of $\mathrm{CdCl}_{2}$ on liver carbohydrate metabolism in Atlantic salmon. The lowest dose they exposed the fish to was $0.01 \mathrm{mg} / \ell$ while $0.1 \mathrm{mg} / \ell$ was the highest exposure dose. Results indicated that exposure to $\mathrm{CdCl}_{2}$ caused a stress response that increased plasma cortisol levels. It has been suggested that these increased cortisol levels sustain increased plasma glucose and lactate levels and that the source for the increased plasma glucose levels may be related to increased glycogenolysis. A dose-dependent fall in liver glycogen levels, as well as a dose-dependent increase in the percentage of glycogen phosphorylase a, and glycogen synthetase a indicated an increased potential for glycogenolysis in $\mathrm{CdCl}_{2}$-exposed fish. There was also a clear increase in PFK activity, which suggests that glycolysis would be favoured, due to an increased energy demand of the liver. The energy would be used to activate one of the metabolic pathways involved in detoxicant activities or the synthesis of metallothioneins in the liver (Soengas et al., 1996).

Carattino et al. (2004) studied the effects of $\mathrm{CdCl}_{2}$ on metabolism through the pentose phosphate pathway in Bufo arenarum toad ovaries (animals exposed to $4 \mu \mathrm{g} / \ell \mathrm{Cd}\left(\mathrm{CdCl}_{2} \cdot 2 \frac{1}{2} \mathrm{H}_{2} \mathrm{O}\right.$ and $100 \mu \mathrm{g} / \ell \mathrm{Cd}\left(\mathrm{CdCl}_{2} \cdot 2 \frac{1}{2} \mathrm{H}_{2} \mathrm{O}\right)$ ) $)$ Results indicated that cadmium has an inhibitory effect on glucose-6-phosphate dehydrogenase activity, but only at concentrations higher than $5 \mathrm{mM}$. Its inhibitory effect on 6-phosphogluconate dehydrogenase activity was very similar. Interesting to note was also that in vivo cadmium only lowered the enzyme activity of 6-phosphogluconate dehydrogenase at the relative low concentration of $4 \mu \mathrm{g} / \ell$. No significant change in enzyme activity was observed at a higher concentration of $100 \mu \mathrm{g} / \ell$. The cadmium exposure had no effect on the activity of glucose-6-phosphate dehydrogenase.

It has been noted that the effect of different oxidative stresses on glucose-6-phosphate dehydrogenase activity varies greatly among the systems and chemical agents studied. Reddy and Bhagyalakshmi (1994) found an increase in the enzyme activity in hepatopancreas and muscle of the edible crab Scylla serrata exposed to $\mathrm{CdCl}_{2}$. In rats injected with $0.4 \mathrm{mg} \mathrm{Cd} / \mathrm{kg}$ of body weight, an initial decrease followed by an increase (after $72 \mathrm{~h}$ of treatment) of both glucose-6-phosphate dehydrogenase and 6phosphogluconate dehydrogenase activities has been observed (Sarkar et al., 1995). Enzyme activities may increase because of induction, after the period necessary for protein synthesis. Sarkar et al. (1995) also observed that the activity of 6-phosphogluconate dehydrogenase was inhibited by $4 \mu \mathrm{g} \mathrm{Cd} / \ell$, but not by $100 \mu \mathrm{g} \mathrm{Cd} / \ell$.
The effects of cadmium on the rat renal cytochrome P450 mono-oxygenase system has been studied and it was reported that chronic exposure of 5 or $50 \mathrm{Cd} / \ell$ (cadmium in the form of aqueous solutions of $\mathrm{CdCl}_{2}$ ) in drinking water affects the kidney cytochrome $\mathrm{P} 450$ dependent mono-oxygenase system and accumulates at low exposures of $2.40 \pm 0.15 \mu \mathrm{g} / \mathrm{g}$ (concentrations used to reflect human exposures) (Plewka et al., 2004). In the kidney $\mathrm{Cd}$ decreases cytochrome $\mathrm{P} 450$ concentrations and inhibits activities of corresponding reductases in environmentally exposed humans. The Cyp 1a1, Cyp2e1 and Cyp 3a1 isoforms of cytochrome $\mathrm{P} 450$ belong to the families responsible for xenobiotic metabolism, the results by the study concluded that detoxification on many substances may be changed during cadmium exposure (Plewka et al, 2004). However, the mechanism of action where cadmium contributes to changes in the cytochrome P450 dependent monooxygenase system is still unknown and further research is needed.

The role of cadmium in the Krebs cycle, glycolysis and protein amino acid metabolism has also been studied. Reddy and Bhagyalakshmi in 1994 investigated the changes in oxidative metabolism in hepatopancreas muscle and hemolymph in crab Scylla serrata after sublethal concentrations of $2.5 \mu \mathrm{m} / \mathrm{m} \ell \mathrm{CdCl}_{2}$ exposure. They found that cadmium affects oxidative metabolism in the following ways:

- Glycogenolysis increased due to increased phosphorylase, which results in decreased levels of glycogen.

- Lactate levels were increased due to decreased lactate dehydrogenase activity, which indicated reduced mobilisation of pyruvate into citric cycle. Krebs cycle enzymes such as succinate dehydrogenase and malate dehydrogenase decreased, which suggest impairment of mitochondrial oxidative metabolism.

- Glucose oxidation was enhanced since glucose-6-phosphate dehydrogenase increased.

- Decreased protein and amino acid levels and increased ammonia, urea and glutamine levels.

- Protease activity was also increased which suggest increased proteolysis.

- Levels of arginase and glutamine synthetase were increased to detoxify ammonia towards production of urea and glutamine.

\section{Copper}

Copper is a metal that also has a significant impact on the environment (Jannaschk et al., 1999). It demonstrates a high affinity for thiol groups and is therefore capable of severely disrupting many metabolic functions in the cell (Hultberg et al., 1998). Copper has an influence on the enzymatic effects of the threonine pathway in Escherichia coli. Even at low concentrations, it can significantly decrease or even block the pathway at several steps (Chassagnole et al., 2003).

Carattino and co-workers (2004) studied the effects of copper on metabolism through the pentose phosphate pathway in Bufo arenarum toad ovaries, animals exposed to $4 \mu \mathrm{g} / \ell \mathrm{Cu}$ $\left(\mathrm{CuSO}_{4} \cdot 5 \mathrm{H}_{2} \mathrm{O}\right)$ and to $100 \mu \mathrm{g} / \ell \mathrm{Cu}\left(\mathrm{CuSO}_{4} \cdot 5 \mathrm{H}_{2} \mathrm{O}\right)$. The authors also found that copper significantly inhibited glucose-6-phosphate dehydrogenase activity in vitro. There was an insignificant increase of activity at low copper concentrations $(0.05 \mathrm{mM}$ to $0.1 \mathrm{mM}$ ), but a sustained inhibition at concentrations above $0.1 \mathrm{mM}$ followed. The effect of copper on 6-phosphogluconate dehydrogenase activity was to some extent different from that observed on glucose-6-phosphate dehydrogenase. A recovery of 
enzyme activity was obtained at copper concentrations higher than $1 \mathrm{mM}$. In the second part of the experiment, the results from the studies on ovarian tissues obtained by surgery after in vivo long-term exposure of the females to copper, the activities of both the dehydrogenase enzymes decreased in a concentration-dependent manner. The enzyme activity of 6-phosphogluconate dehydrogenase was actually decreased by approximately $90 \%$.

The pentose phosphate pathway ${ }^{14} \mathrm{CO}_{2}$ evolution was decreased in oocytes that were simultaneously injected with $6.3 \times 10^{-3} \mathrm{mM}$ copper and radioactive glucose. The $\mathrm{CO}_{2}$ evolution can be used as a measure of the pathway's activity. Therefore it can be said that exposure to copper reduces the pathway's activity. Results of long-term exposure to copper and the in vivo production of $\mathrm{CO}_{2}$, suggested that both the activities of 6-phosphogluconate dehydrogenase and glucose-6-phosphate dehydrogenase could be used as a biomarker for copper toxicity in toad oocytes.

In a study conducted by Gebhard et al. (2001), concentrations of copper (using $\mathrm{CuCl}_{2}$ ) ranging from $1 \mu \mathrm{M}$ to $1 \mathrm{mM}$, displayed an inhibitory effect on eight different phosphofructokinases (PFKs) with a broad phylogenetic range.

\section{Fluoride and its interaction with aluminium}

Although fluoride is currently added to drinking water, it may have a synergistic interaction with the metal aluminium. Fluoride is a component of pollutants, both gaseous and particulate, that are emitted from aluminium ore processors and industries that manufacture textiles, fertilisers, rayon, paper, pulp and pharmaceuticals (Rai et al., 1996). Fluoride accumulates in the exoskeleton of aquatic invertebrates and in the bone tissue of fish. The toxic action of fluoride is based on the fact that fluoride ions act as enzymatic poisons that inhibit enzyme activity and, ultimately, interrupt metabolic processes such as glycolysis and the synthesis of proteins. Its toxicity to aquatic invertebrates and fish increases with increasing fluoride concentration, exposure time and water temperature, and decreases with increasing body size and water content of calcium and chloride (Camargo, 2003).

Aluminium constitutes approximately $8 \%$ of the soil minerals of the earth. It tends to remain insoluble in the form of hydroxides and complex aluminosilicates, but acidification increases the level of free aluminium in the soil and lakes. Its availability and toxicity is regulated both by $\mathrm{pH}$ and the presence of ligands such as fluorides, phosphates, silicates and carboxylates. The smallest shift in $\mathrm{pH}$ can have an extreme effect on Al specification because aluminium occurs in many different forms. Aluminium toxicity is enhanced in acidic environments that are contaminated with fluoride (Rai et al., 1996).

Fluoride is known to inhibit a large number of processes, such as photosynthesis, respiration, protein synthesis and enzyme activities of higher plants, green algae, cyanobacteria and bacteria and the levels of fluoride that affect these organisms vary according to the type of organism. In the presence of Al, fluoride inhibits a number of ATPases. Fluoride forms tetra-coordinated fluoroaluminate complexes with aluminium at low $\mathrm{pH}$ values $\left(3 \mathrm{mM} \mathrm{NaF}+\mathrm{A}_{1 \mathrm{CI}}\right)$. These complexes inhibit cyanobacterial metabolism by binding at the phosphate binding sites. This inhibition can be achieved because fluoroaluminate has a similar structure to phosphate (Rai et al., 1996). Rai et al. (1996) conducted a study on the combined effects of fluoride, aluminium and acidification on
$N$. linckia. The authors suggested that fluoroaluminate might bind with ADP, GDP and cations, which cause the translocation of ATPases and the inhibition of metabolic energy synthesis and release, thereby having an affect on physiological processes that require energy and on translocation of ions essential for algal growth and multiplication. The reduction of ATP at low pH could possibly be due to the inhibition of the electron transport chain because this is the major energy producing system in cyanobacteria. The reduction of ATP content brings about the inhibition of the assimilation of ${ }^{14} \mathrm{C}$ at a low $\mathrm{pH}$. This causes a decrease in the availability of carbon skeletons. It is postulated that this is responsible for the reduction in nitrogenase and nitrate reductase activities. This reduction in energy may also lead to an inhibition of other enzymes such as glutamine synthetase and urease (Rai et al., 1996) and indicates where fluoride and aluminium influence the metabolic pathways.

\section{Iron}

Iron modifies the expression of the citric acid cycle enzyme aconitase via a mechanism involving iron regulatory proteins. Oexle et al. (1999) studied the consequences of iron exposure and particularly iron chloride $\left(\mathrm{FeCl}_{2}\right)\left(100 \mu \mathrm{M} \mathrm{FeCl}_{2}\right)$ on citric acid cycle activity, oxidative phosphorylation and mitochondrial respiration in the human cell line K-562. Fe exposure was shown to increase the activity of mitochondrial aconitase. It also positively affects three other citric acid cycle enzymes, namely citrate synthase, isocitric dehydrogenase, and succinate dehydrogenase. From these results the authors suggested that there is a complex interaction between Fe homeostasis, oxygen supply and cellular energy metabolism and these interactions are not fully understood as yet.

Consequently, exposure to iron results in the increased formation of reducing equivalents (NADH) by the citric acid cycle, and as a result, increased mitochondrial oxygen consumption and ATP formation via oxidative phosphorylation. This down regulates of the use of glucose. These results illustrate an intricate interaction between iron homeostasis, oxygen supply and cellular energy metabolism in human cells (Oexle et al., 1999).

\section{Zinc}

Zinc is a ubiquitous element essential for normal enzymatic function in metabolic pathways. Zinc is given credit for the treatment of skin disorders and the common cold. But excessive zinc ingestion may cause reversible anaemia and damage to the pancreas and kidneys (Hein, 2003). There is also evidence that zinc may enhance the activity of Phase 2 glutathion-S-transferase in the fat body and malpighian tubules of the Spodoptera exigua larvae after $200 \mu \mathrm{g} / \mathrm{g}$ zinc intoxication (Kafel et al., 2003).

Zinc is also known for its inhibition of glycolysis, tricarboxylic acid cycle, electron transport chain and glutamate release. The two glycolytic enzymes that might be inhibited by increased zinc concentrations are glyceraldehyde-3-phosphate dehydrogenase (GAPDH) and phosphofructokinase. It was shown in cultured cortical neurons that elevated zinc concentrations result in a build-up of glycolytic metabolites upstream of GAPDH and depleted intermediate products downstream and results in a lower ATP production.

Data report that zinc $\left(\mathrm{Zn}^{2+}\right)$ also inhibits $\alpha$-ketoglutarate dehydrogenase complex (KGDHC) and lipoamide dehydro- 
genase (LADH) subunit of the tricarboxylic acid cycle. Zinc is also known for its inhibition of the electron transport chain between cytochrome b\&c1 (Dineley et al., 2003).

The influence of zinc on the pentose-phosphate pathway and xenobiotic metabolism is studied by Naab and co-workers (2001) to investigate the long-term toxic effects of zinc on the metabolism of female amphibian Bufo arenarum, by concentrating on the activities of the key enzyme of the pentose-phosphate pathway, glucose-6-phosphae dehydrogenase and glutathione contents in the liver and ovary after zinc exposure $\left(47 \mathrm{~g} / \mathrm{L} \mathrm{Zn}^{2+}\left(\mathrm{ZnSO}_{4} \cdot \mathrm{H}_{2} \mathrm{O}\right)\right)$ in Ringer solution. Results showed that glucose-6-phosphate dehydrogenase activity decrease and endogenous glutathione content increased in the ovary. Zinc binds then to metallothioneins to protect the liver from toxicity. However, in the ovary high-molecular weight proteins such as glucose-6-phosphate dehydrogenase, should be able to bind zinc, leading to oxidative stress responsible for the observed increased glutathione levels. Finally, inhibition of the pentose phosphate pathway by zinc in this frog species may result in reproductive failure (Naab et al., 2001).

\section{Lead}

Lead contamination of the environment constitutes one of the major ecological problems. Lead can be found in the air, in foods grown around industrial areas, tap water, tobacco smoke and in a wide variety of other products (Pouls, 2002). It has been reported that lead ions $\left(\mathrm{Pb}^{2+} / \mathrm{Pb}(\mathrm{II})\right)$ result in changes in the activity of numerous enzymes by disturbing metabolic pathways including the inhibition of glycolysis, haem and globin synthesis which thereby influence the metabolism of erythrocytes (Baranowska-Bosiacka et al., 2000).

\section{Arsenic}

The source of arsenic exposure can be found in a variety of products, some of these sources include: Air pollution, chemical processing, drinking water, herbicides and metal ore smelting. The target tissues for this metal include most organs but especially the gastrointestinal system, lungs and skin (Pouls, 2002). Furthermore, arsenic (particularly $\mathrm{As}^{3+}$ ) is considered a human carcinogen (IARC, 1987; ATSDR, 1999; NRC, 1999; Abernathy et al., 1999) and is present in high concentrations at many toxic waste sites. Groundwater and well water from natural sources may be contaminated by arsenic from the disposal of arsenic-containing compounds from industrial and mining activities. However, certain geological formations contain high levels of arsenic that may leach into groundwater, to wells and eventually other public water supplies (Klaue and Blum, 1999). This has been a major problem in areas of Taiwan, South America, India, and Pakistan where populations had a significant increase in the risk of lung, skin, liver, bladder, and other cancers associated with high levels of arsenic in drinking water (IARC, 1987; ATSDR, 1999; NRC, 1999; Abernathy et al., 1999). Similar regions of natural arsenic were found in the USA in areas of New Hampshire, Michigan, Nevada, and California (Karagas et al., 1998; Peters et al., 1999). Many wells have arsenic concentrations in the range of 100 to $800 \mu \mathrm{g} / \ell$ (Karagas et al., 1998; Peters et al., 1999) and the US Environmental Protection Agency's (EPA's) new proposed standard is $0.14 \mu \mathrm{M}$.

A study was also done to investigate the effects of metals such as cadmium and arsenic on the expression of the multidrug resistance associated protein 2 (MRP2) a major hepatic transporter. $\mathrm{CdCl}_{2}$ and sodium arsenite $\left(\mathrm{NaAsO}_{2}\right)$ was used in the experiments. Results concluded that arsenic but not cadmium up regulates MRP2 gene expression in rat and human hepatocytes, which contribute to enhanced biliary secretion of xenobiotics and endogenous compounds handled by MRP2 (Vernhet et al., 2001), and may be linked to alteration of cellular glutathione levels. But in contrast, exposure of sodium, arsenic has been shown to decrease induction of enzymatic activities associated with hepatic Cytochrome P450's in xenobiotic treated rat hepatocytes and result in down-regulation in drug metabolism (Jacobs et al., 1999).

Reichl and co-workers (1988) investigated the effects of arsenic on carbohydrate metabolism of male guinea pig livers after a single dose of $\mathrm{As}_{2} \mathrm{O}_{3} 10 \mathrm{mg} / \mathrm{kg}$ or $2.5 \mathrm{mg} / \mathrm{kg}$ on 5 consecutive days. Results showed a decreased level of fructose-1.6-diphosphate and glycerolaldehyde-3-phosphate and an increased rate of phosphoenol-pyruvate and pyruvate after single doses of As. The most prominent finding was the depletion of total carbohydrate content after repeated $\mathrm{As}_{2} \mathrm{O}_{3}$ administration and concluded that it was due to the depletion of glycogen.

Kaltreider et al., 2001 demonstrated that a single, low, not obviously toxic dose of arsenite $\left(\mathrm{H}_{3} \mathrm{AsO}_{3}\right.$ or arsenic (III) oxide) significantly and preferentially altered both the basal and inducible mRNA expression of the model hormone-inducible phosphoenolpyruvate carboxykinase (PEPCK) gene, both in vivo and in vitro (Hamilton, 1998). The PEPCK gene is primarily transcriptionally regulated, and its protein product, the cytosolic PEPCK enzyme, is the rate-limiting step in gluconeogenesis (Faber et al., 1993; Granner, 1991). Kaltreider et al. (2001) also demonstrated that these non-toxic doses of arsenite can interact directly with the glucocorticoid receptor (GR) complexes and selectively inhibit GR-mediated transcription, which is associated with altered nuclear function. Hamilton's group (1998) subsequently demonstrated that arsenite has similar effects on all the steroid receptors (Mead, 2005) thereby confirming that arsenite is a potent endocrine disruptor.

\section{Manganese}

Manganese is an essential nutrient for optimal cellular function, and is known to cause neurotoxicity by increasing oxidative stress and also disturbing neurotransmitter metabolism (Erikson et al., 2004). Manganese is typically used in the manufacture of steel, stainless steel and other metal alloys. Individuals may be exposed to manganese dust by inhalation or to manganese salts dissolved in water. Manganese and cadmium $\left(\mathrm{CdCl}_{2}\right.$ $(2.5 \mathrm{mg} / \mathrm{kg})$ body weight or $\mathrm{MnCl}_{2}(2.0 \mathrm{mg} / \mathrm{kg}$ body weight $)$ has reported an increase in glutathion-S-transferase (GST) activity that plays a role in xenobiotic metabolism (Casalino et al., 2004).

Manganese preferentially accumulates in the mitochondria that may lead to uncoupling of oxidative phosphorylation in neuronal cells. Human neuroblastoma (SK-N-SH) and astrocytoma (U87) cells were used to investigate the alterations in energymetabolising enzymes. Cells were exposed to $\mathrm{MnCl}_{2} 0.01$ to $4.0 \mathrm{mM}$ for $48 \mathrm{~h}$ and induced cell death in a concentration-timedependent manner. Results showed a dose-related decrease in activities of: Hexokinase, pyruvatekinase, lactate dehydrogenase, citrate synthase and malate dehydrogenase. Hexokinase enzyme, the first and highly-regulated enzyme in brain 


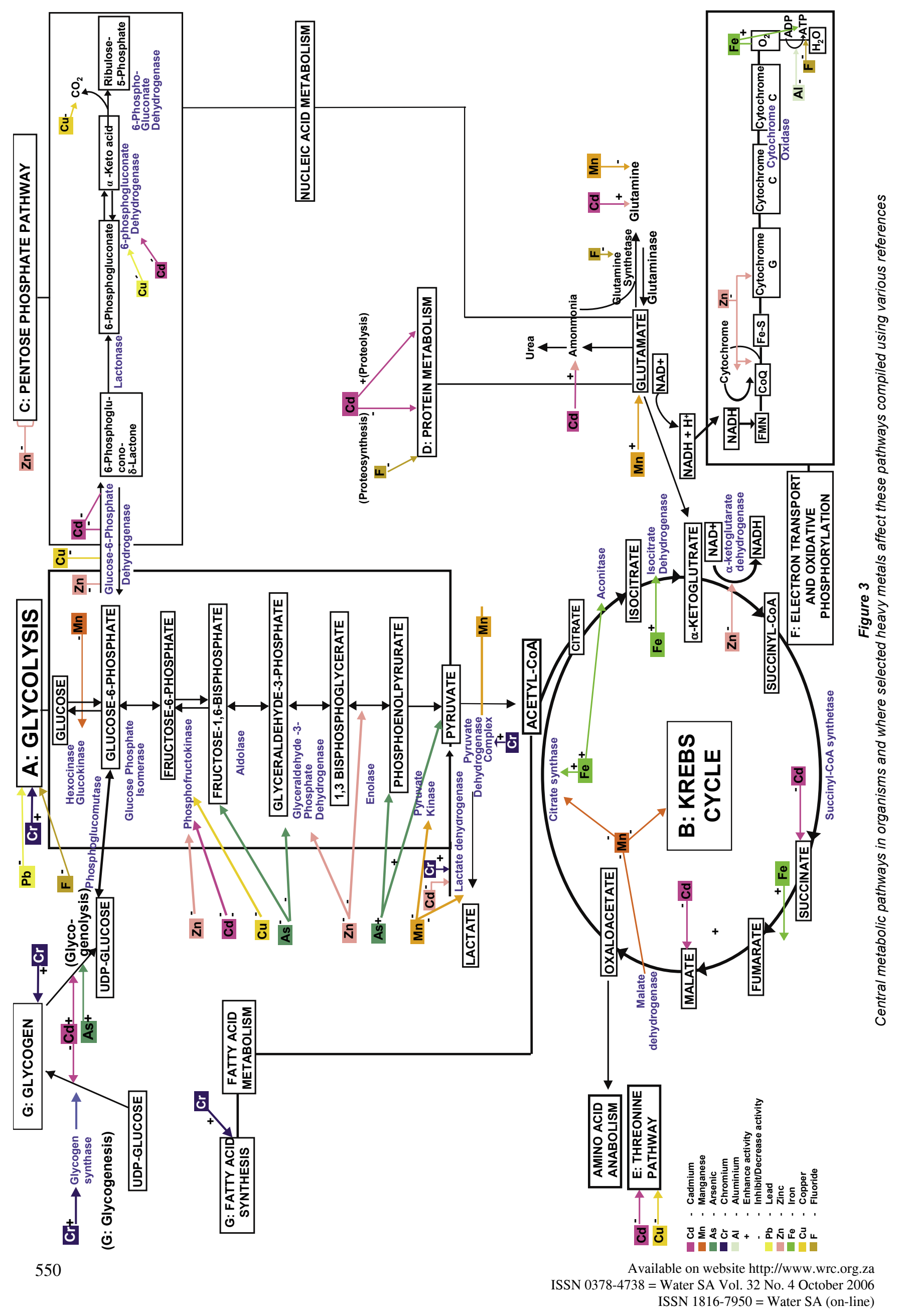


glycolysis, was the most affected in SK-N-SH cells. Citrate synthase and Pyruvate kinase were more vulnerable than other enzymes in the U87 cells (Malthankar et al., 2004).

It was also found in a study done by Zwingmann and coworkers in 2003 that there is an impaired flux of [1-13C] glucose through pyruvate dehydrogenase, which was associated with Krebs cycle inhibition, depletion of [4-13C] glutamate and $[13 \mathrm{C}]$ glutathion after manganese neurotoxicity. Neurons were treated for $5 \mathrm{~d}$ with $100 \mu \mathrm{mol} / \ell \mathrm{MnCl}_{2}$. Stimulated glucose metabolism protects astrocytes against oxidative stress and leads to increased production of glutamate, lactate and glutathion. However, manganese intoxication inhibited synthesis and release of glutamine, which result in aggravated neuronal energy failure.

\section{Chromium}

Chromium can be found in the production of steel electrolytic chromium plating, in the manufacture of refractory bricks and other chromium alloys. Chromium compounds pass through many tissues, including red blood cells, kidney, liver, spleen and bone (Costa Klein, 2006). Chromium also plays a role in glycolysis and the Krebs cycle. Davies et al., 1985 studied the effects of chromium $\left(\mathrm{Cr}^{3+}\right)$ on the glucose tolerance factor (GTF) of brewers yeast performed with isolated adipocytes. In the presence of chromium the activities of GTF substances increased, which caused an increase in glycolysis in yeast and increased glycolysis and fatty acid synthesis in adipocytes.

The toxic effects of hexavalent chromium $\left(\mathrm{Cr}^{6+} / \mathrm{Cr}(\mathrm{VI})\right)$ at sublethal concentrations in freshwater teleost fish on the activities of lactate dehydrogenase (LDH) pyruvate dehydrogenase $(\mathrm{PDH})$ and succinate dehydrogenase (SDH) were also investigated. It was found that muscle glycogen increased and liver glycogen decreased. The activities of LDH and PDH showed that the rate of glycolysis increased in muscle tissues (Sastry and Tyagi, 1982).

\section{Results and discussion}

From the above-mentioned literature, it is clear that the metals reviewed in this article influence the metabolic pathways extensively. A diagram was drawn to indicate where each of the reviewed metals influences the metabolic pathways (see Fig. 3).

Gycolosis, the pentose phosphate pathway, and the KREBS cycle are three of the most important metabolic pathways in the body. However, protein metabolism as well as the electron transport system is involved in adequate functioning of the body and if these processes are interfered with the body may suffer oxidative stress. Amino acid anabolism as well as the threonine pathway is also affected by the reviewed metals.

Glycolysis (Fig. 3, Label A) is the metabolic pathway where glucose (a 6-carbon molecule) is anaerobically broken down to pyruvate (which is a 3 -carbon molecule). Glucose is converted to pyruvate in a number of steps. Once pyruvate is formed, it can be converted to carbon dioxide and water under aerobic conditions. Under anaerobic conditions, it can be converted to lactate, or ethyl alcohol (Campbell, 1999). This pathway is influenced extensively by the reviewed metals. It seems in particular that the enzymes involved in converting glucose in the pathway to pyruvate, are influenced. Manganese negatively affects hexocinase and glucosinase early in the pathway, but also pyruvate kinase later in the pathway. Zinc, cadmium and copper influence phosphofructokinase, while the two glycolytic enzymes (glyceraldehyde-3-phosphate dehydrogenase (GAPDH) and phosphofructokinase) might be inhibited by increased zinc concentrations are (Naab et al., 2001). Furthermore, arsenic influences fructose-1, 6-bisphosphate, glyceraldehyde-3-phosphate, phosphor-enolpyrurate as well as pyruvate.

Manganese also influences lactate dehydrogenase that converts pyruvate to lactate. The metals cadmium and chromium affect the opposing pathway where lactate is converted to pyruvate.

The citric acid cycle also called the KREBS cycle (Fig. 3, Label B) is an amphibolic pathway, meaning it plays a role in catabolism as well as anabolism. Pyruvate that is produced in glycolysis is transformed into acetyl-CoA by oxidative decarboxylation. Acetyl-CoA reacts with oxaloacetate and enters the citric acid cycle to produce citrate. There are two further oxidative decarboxylation reactions, transforming the 6-carbon citrate into succinate, a 4-carbon compound. Oxaloacetate is regenerated from succinate to complete the cycle in a process that involves two oxidation reactions. The electron acceptors in the oxidation reactions are NAD+ and FAD (Campbell, 1999).

Pyruvate, the end-product of glycolysis, via the pyruvate dehydrogenase complex of enzymes, is converted to acetylCoA (involved in the first phases of the KREBS cycle). The KREBS cycle is affected by iron, zinc, cadmium as well as manganese. Exposure to iron in particular, results in the increased formation of reducing equivalents (NADH) by the citric acid cycle, and as a result, increased mitochondrial oxygen consumption and ATP formation via oxidative phosphorylation. This down-regulates the use of glucose. These results illustrate an intricate interaction between iron homeostasis, oxygen supply and cellular energy metabolism in human cells (Oexle et al., 1999).

The pentose phosphate pathway (Fig. 3, Label C) is an alternative pathway to glycolysis. It begins with a series of oxidation reactions that produce 5 -carbon sugars, such as ribose, which play an important role in the structure of nucleic acids. The remainder of the pathway involves non-oxidative reshuffling of the carbon skeletons of the sugars. Products of the non-oxidative reactions include fructose-6-phosphate and glyceraldehydes-3phosphate, which play a role in glycolysis. ATP production is not the main concern of the pentose phosphate pathway, as it is in glycolysis. An important feature of the pentose phosphate pathway is the production of NADPH, which is a reducing agent in biosynthesis (Campbell, 1999).

Copper, cadmium and zinc influence enzymes involved in this pathway (Naab et al., 2001; Carattino et al. 2004). Enzymes that are affected are glucose-6-phosphate dehydrogenase, 6phosphogluconate dehydrogenase and 6-phosphogluconate dehydrogenase and therefore copper, cadmium and zinc reduces the pathway's activity.

Protein metabolism (Fig. 3, Label D) is important for all living cells in the body. This process is influenced by fluoride, cadmium and manganese. Fluoride in particular leads to the inhibition of enzymes such as glutamine synthetase and urease (Rai et al., 1996).

The chemical reactions resulting in the formation of threonine (2-amino-3-hydroxybutyric acid) is named the threonine pathway (Fig. 3, Label E). Threonine is a polar, uncharged, essential amino acid found in peptide linkage in proteins. This pathway is influenced by cadmium and it can significantly impair or even block the pathway at several steps (Chassagnole et al., 2003). This pathway is also influenced by copper. 
In the final stages of aerobic metabolism, electrons are transported from NADH to oxygen in a series of oxidation-reduction reactions known as the electron transport chain (Label F). These reactions create a $\mathrm{pH}$ gradient across the inner mitochondrial membrane. The $\mathrm{pH}$ gradient drives the process of oxidative phosphorylation, which produces ATP from ADP. The two processes are united by the mechanism of chemiosmotic coupling. This system is influenced by zinc, iron, aluminium and fluoride.

Fatty acid synthesis, glycogen synthesis (Label G) is influenced by chromium.

\section{Conclusion}

We conclude by suggesting that metals, and particularly the ones discussed in this article, may affect all parts of the central metabolic pathway by inhibiting or interfering with enzyme function in particular. Figure 3 suggests that glycolysis, the Krebs cycle, nucleic acid metabolism, protein metabolism as well as the pentose phosphate pathway are the major pathways affected. Metal pollutants in the environment will eventually end up in our water sources and by contaminating water, pose a risk to human and aquatic health. The guidelines for metal concentrations in water systems not only set limits to target water quality ranges (TWQR), but also provide an indication of the levels at which acute or chronic effects (AEV, CEV) will become evident. The linking of metals to the basic pathways for energy generation adds a new approach to our understanding of the pathophysiology of adverse health effects. It also seems crucial to further investigate the impact of these metals on the central metabolic pathway of exposed organisms as possible biomarkers, as these may possibly provide earlier indications of adverse health effects at lower concentrations than the no-observedadverse-effect-levels (NOAEL)

\section{Acknowledgments}

We would like to thank the National Research Foundation of South Africa (NRF) for funding both E Pretorius (Unique South African Research Opportunities) and MS Bornman (Sustainable Development); as well as the Water Research Commission for funding MS Bornman.

\section{References}

ABERNATHY CO, LIU YP, LONGFELLOW D, APOSHIAN HV, BECK B, FOWLER B, GOYER R, MENZER R, ROSSMAN T, THOMPSON C and WAALKES M (1999) Arsenic: health effects, mechanisms of actions, and research issues. Environ. Health Perspect. 107 593-597.

ALMEIDA JA, NOVELLI ELB, DAL PAI SILVA M, and ALVES JÚNIOR R (2001) Environmental cadmium exposure and metabolic responses of the Nile tilapia, Oreochromis niloticus. Environ. Pollut. 114 169-175.

ATSDR (1999) Toxicological Profile for Arsenic (Update). Washington DC: Agency for Toxic Substances and Disease Registry, USDHHS, PHS.

BAKER JR, SATARUG S, URBENJAPOL S, EDWARDS RJ, WILLIAMS DJ, MOORE MR and REILLY PEB (2002) Associations between human liver and kidney cadmium content and immunochemically detected CYP4A11 apoprotein. Biochem. Pharmacol. 63 693-696.

BAKER JR, SATARUG S, EDWARDS RJ, MOORE MR, WILLIAMS DJ and REILLY PEB (2003) Potential for early involvement of CYP isoforms in aspects of human cadmium toxicity. Toxicol. Lett. 137 $85-93$

BARANOWSKA-BOSIACKA I, HLYNCZAK AJ and MACHALINSKI B (2000) The impact of lead ions on metabolism of erythrocytes. Med. Pr. 51 (1) 59-65.

DUFFUS JH (2002) Heavy metals - a meaningless term? Pure Appl. Chem. 74 793-807.

CAMARGO JA (2003) Fluoride toxicity to aquatic organisms: A review. Chemosphere 50 251-264.

CAMPBELL MK (1999) Biochemistry (3 ${ }^{\text {rd }}$ edn.). Harcourt College Publishers.

CARATTINO MD, PERALTA S, PÉREZ-COLL C, NAAB F, BURLÓN A, KREINER AJ, PRELLER AF and FONOVICH DE SCHROEDER TM (2004) Effects of long-term exposure to $\mathrm{Cu}^{2+}$ and $\mathrm{Cd}^{2+}$ on the pentose phosphate pathway dehydrogenase activities in the ovary of adult Bufo arenarum: Possible role as biomarker for $\mathrm{Cu}^{2+}$ toxicity. Ecotoxicol. Environ. Saf. 57 311-318.

CASALINO E, SBLANO C, LANDRISCINA V, CALZARETTI G and LANDRISCINA C (2004) Rat liver glutathione S-transferase activity stimulation following acute cadmium or manganese intoxication. Toxicol. 200 29-38.

CHASSAGNOLE C, QUENTIN E, FELL DA, DE ATUARI P and MAZAT J-P (2003) Model-driven acquisition: Dynamic stimulation of pollutant effects on the threonine pathway in Escherichia coli. Comptes Rendus Biologies 326 501-508.

CHENG S (2003) Heavy metal pollution in China: origin, pattern and control. Environ. Sci. Pollut. Res. Int. 10 (3) 192-198.

COSTA M and KLEIN CB (2006) Toxicity and carcinogenicity of chromium compounds in humans. Crit. Rev. Toxicol. 36 155-163.

CODINA JC, PEREZ-GARCIA A and DE VICENTE A (1994) Detection of heavy metal toxicity and genotoxicity in wastewaters by microbial assay. Water Sci. Technol. 30 145-151.

DAVIES DM, HOLDSWORTH ES and SHERRIFF JL (1985) The isolation if glucose tolerance factors from brewers yeast and their relationship to chromium. Biochem. Med. 33 (3) 297-311.

DINELEY KE, VOTYAKOVA TV and REYNOLDS IJ (2003) Zinc inhibition of cellular energy production: Implications for mitochondria and neurodegeneration. J. Neurochem. 85 563-570.

DONATO MT and CASTELL JV (2003) Strategies and molecular probes to investigate the role of cytochrome $\mathrm{P} 450$ in drug metabolism. Clin. Pharmacokinet. 42 (2) 153-178.

DWAF (1986) Management of the Water Resources of the Republic of South Africa. Department of Water Affairs, Pretoria.

DWAF (1994) White Paper on Water Supply and Sanitation Policy. DWAF, November 1994.

ELLIS KV (1989) Surface Water Pollution and its Control. The MacMillan Press Ltd. London.

ERIKSON KM, DOBSON AW, DORMAN DC and ASCHNER M (2004) Manganese exposure and induced oxidative stress in the rat brain. Sci. Total Environ. 334-335 409-416

FABER S, O'BRIEN RM, IMAI E, GRANNER DK and CHALKLEY $\mathrm{R}$ (1993) Dynamic aspects of DNA/protein interactions in the transcriptional initiation complex and the hormone-responsive domains of the phosphoenolpyruvate carboxykinase promoter in vivo. J. Biol. Chem. 268 24976-24985.

GEBHARD S, RONIMUS RS and MORGAN HW (2001) Inhibition of phosphofructokinase by copper (II). FEMS Microbiol. Lett. 197 105-109.

GRANNER D, O'BRIEN R, IMAI E, FOREST C, MITCHELL J and LUCAS P (1991) Complex hormone response unit regulating transcription of the phosphoenolpyruvate carboxykinase gene: From metabolic pathways to molecular biology. Recent. Prog. Horm. Res. 47 319-346.

HAMILTON JW, KALTREIDER RC, BAJENOVA OV, IHNAT MA, McCAFFREY J, TURPIE BW, ROWELL EE, OH J, NEMETH MJ, PESCE CA and LARIVIERE JP (1998) Molecular basis for effects of carcinogenic heavy metals on inducible gene expression. Environ. Health Perspect. 106 (suppl 4) 1005-1015.

HEATH RGM and CLAASSEN M (1999) An Overview of the Pesticide and Metal Levels Present in Populations of the Larger Indigenous Fish Species of Selected South African Rivers. WRC Report No 428/1/99. Water Research Commission, Pretoria, South Africa. 
HEIN MS (2003) Copper deficiency anemia and nephrosis in zinc-toxicity: A case report. SDJ Med. 56 (4) 143-147.

HENSON MC and CHEDRESE PJ (2004) Endocrine disruption by cadmium, a common environmental toxicant with paradoxical effects on reproduction. Exp. Biol. Med. 229 385-392.

HODSON ME (2004) Heavy metals - geochemical bogey man? Environ. Pollut. 129 341-343.

HUANG GH and XIA J (2001) Barriers to sustainable water-quality management. J. Environ. Manage. 61 1-23.

HULTBERG B, ANDERSSON A and ISAKSSON A (1998) Alterations of thiol metabolism in human cell lines induced by low amounts of copper, mercury or cadmium ions. Toxicol. 126 203-212.

IARC (1987) Arsenic and arsenic compounds (Group 1). In: IARC Monographs on the Evaluation of Carcinogenic Risk of Chemicals to Humans, Vol 7. Lyon: IARC.

IUPAC (2002) 'Heavy metals' a meaningless term? Technical report Pure Appl. Chem. 74 (5) 793-807.

IYER KR and SINZ MW (1999) Hepatocyte Research Report: Characterization of Phase I and Phase II hepatic drug metabolism activities in a panel of human liver preparations. Chem. Biol. Interact. 118 (2) 151-169.

JACOBS JM, NICHOLS CE, ANDREW AS, MAREK DE, WOOD SG, SINCLAIR DR, WRIGHTON SA, KOSTRUBSKY VE and SINCLAIR JF (1999) Effect of arsenite on induction of CYP1A, CYP2B and CYP3A in primary cultures of rat hepatocytes. Toxicol. Appl. Pharmacol. 157 51-59.

JANNASCHK D, BURGOS M, CENTERLLES JJ, OVADI J and CASCANTE M (1999) Application of metabolic control analysis to the study of toxic effects of copper in muscle glycolysis. FEBS Lett. 445 144-148.

KAFEL A, BEDNARSKA K, AUGUSTYNIAK M, WITAS I and SZULIÑSKA E (2003) Activity of glutathion S-transferase in Spodoptera exigua larvae exposed to cadmium and zinc in two subsequent generations. Environ. Int. 28 683-686.

KALTREIDER RC, DAVIS AM, LARIVIERE JP and HAMILTON JW (2001) Arsenic alters the function of the glucocorticoid receptor as a transcription factor. Environ Health Perspect. 109 (3) 245-251.

KARAGAS MR, TOSTESON TD, BLUM J, MORRIS JS, BARON JA and KLAUE B (1998) Design of an epidemiologic study of drinking water arsenic exposure and skin and bladder cancer risk in a U.S. population. Environ. Health Perspect. 106 (4) 1047-1050.

KHAN S, KHAN MA, BHATNAGAR D, UADAV P and SARKAR S (1991) Zinc protection against lipid peroxidation from cadmium. Indian J. Exp. Biol. 29 823-825.

KLAASSEN CD (2001) (ed.) Casarett and Doull's Toxicology: The Basic Science of Poisons ( $6^{\text {th }}$ edn.) New York: McGraw-Hill.

KLAUE B and BLUM JD (1999) Trace analyses of arsenic in drinking water by induced coupled plasma mass spectrometry: high resolution versus hydride generation. Anal. Chem. 71 1408-1414.

LIVINGSTONE DR (1998) The fate of organic xenobiotics in aquatic ecosystems: quantitative and qualitative differences in biotransformation by invertebrates and fish. Comp. Biochem. Physiol. A. Mol. Integr. Physiol. 120 43-49.

LUOMA SN and RAINBOW PS (2005) Why is metal bioaccumulation so variable? Biodynamics as a unifying concept. Environ. Sci. Technol. 39 (7) 1921-1931.

MALTHANKAR GV, WHITE BK, BHUSHAN A, DANIELS CK, RODNICK KJ and LAI JC (2004) Differential lowering by manganese treatment of activities of glycolytic and tricarboxylic acid (TCA) cycle enzymes investigated in neuroblastoma and astrocyoma cells is associated with manganese - induced cell death. Neurochem. Res. 29 (4) 709-717.

MEAD MN (2005) Arsenic in search of an antidote to a global poison. Environ. Health Perspect. 113 (6) A378-386.

MEHMOOD Z, WILLIAMSON MP, KELLY DE and KELLY SL (1996) Metabolism of organochlorine pesticides: The role of human cytochrome P450 3A4. Chemosphere 33(4) 759-769.

MOORE MR (2004) A commentary on the impacts of metals and metalloids in the environment upon the metabolism of drugs and chemicals. Toxicol. Lett. 148 153-158.

NAAB F, VOLCOMIRSKY M, BURLÓN A, CARABALLO ME, DEBRAY M, KESQUE JM, KREINER AJ, OZAFRÁN MJ,
SCHUFF JA, STOLAIR P, VÁZQUEZ ME, DAVIDSON J, DAVIDSON M and FONOVICH DE SCHROEDER TM (2001) Metabolic alterations without metal accumulation in ovary of adult Bufo arenarum females, observed after long-term exposure to $\mathrm{Zn}^{2+}$, followed by toxicity to embryos. Arch. Environ. Contam. Toxicol. 41 (2) 201-207.

NRC (1999) Arsenic in Drinking Water. Washington, DC: National Research Council.

OEXLE H, GNAIGER E and WEISS G (1999) Iron-dependent changes in cellular energy metabolism: influence on citric acid cycle and oxidative phosphorylation. Biochim. Biophys. Acta 1413 99-107.

OHE T, WATANABE T and WAKABAYASHI K (2004) Mutagens in surface waters: A review. Mutat. Res. 567 (2-3) 109-149.

PETERS SC, BLUM JD, KLAUE B and KARAGAS MR (1999) Arsenic occurrence in New Hampshire drinking water. Environ. Sci. Technol. 33 1328-1333.

PLEWKA A, PLEWKA D, NOWACZYK G, BRZÓSKA MM, KAMIŃSKI M and MONIUSZKO-JAKONIUK J (2004) Effects of chronic exposure to cadmium on renal cytochrome P450-dependent mono-oxygenase system in rats. Arch. Toxicol. 78194-200

POULS M (2002) Oral chelation and nutritional replacement therapy of heavy metal toxicity and cardiovascular conditions. University of Michigan. Http://www.heall.com/healingnews/may/heavy metals. html (accessed on 5 September 2006).

RAI LC, HUSAINI Y and MALLICK N (1996) Physiological and biochemical responses of Nostoc linckia to combined effects of aluminium, fluoride and acidification. Environ. Exp. Bot. 36 (1) 1-12.

REDDY PS and BHAGYALAKSHMI A (1994) Changes in oxidative metabolism in selected tissues of the crab (Scylla serrata) in response to cadmium toxicity. Ecotoxicol. Environ. Saf. 29 (3) $255-$ 264.

REICHL FX, SZINICZ I, KREPPEL H and FORTH W (1988) Effect of arsenic on carbohydrate metabolism after single or repeated injection in guinea pigs. Arch. Toxicol. 62 (6) 473-475.

SANCHEZ-GALAN, LINDE AR, AYLLON F and GARCIA-VAZQUEZ E (2001) Induction of micronuclei in Eel (Anguilla anuilla L.) by heavy metals. Ecotoxicol. Environ. Saf. 49 139-143.

SARKAR S, YADAV P, TRIVEDI R, BANSAL AK and BHATNAGAR D (1995) Cadmium-induced lipid peroxidation and the status of the antioxidant system in rat tissues. J. Trace Elem. Med. Biol. 9 144-149.

SASTRY KV and TYAGI S (1982) Toxic effects of chromium in a fresh water teleost fish, Channa punctatus. Toxicol. Lett. 1 (1-2) 17-21.

SCHOKET B, PAPP G and LÉVAY K (2001) Impact of metabolic genotypes on levels of biomarkers of genotoxic exposure. Mutat. Res. 482 57-69.

SOENGAS JL, AGRA-LAGO MJ, CARBALLO B, ANDRÉS MD and VEIRA JAR (1996) Effect of an acute exposure to sublethal concentrations of cadmium on liver carbohydrate metabolism of Atlantic salmon (Salmo salar). Bull. Environ. Contam. Toxicol. 57 635-631.

TALALAY P (2000) Chemoprotection against cancer by induction of Phase 2 enzymes (mini-review). Biofactors 12 5-11.

TALALAY P and FAHEY JW (2001) Phytochemicals from cruciferous plants protect against cancer by modulating carcinogen metabolism. Am. Soc. Nutrit. Sci. 0022-3166/01.

TIMBRELL J (2000) Principles of Biochemical Toxicology ( $3^{\text {rd }}$ edn.). Taylor \& Francis, London and New York.

UNITED NATIONS ENVIRONMENT PROGRAMME (2004) Vital Water Graphics. http://www.unep.org/vitalwater/references.htm (accessed on 5 September 2006)

UNITED STATES ENVIRONMENTAL PROTECTION AGENCY (2006) Private Drinking water wells. http://www.epa.gov/safewater/privatewells/health.htm1 (accessed on 5 September 2006).

VAGLIO A and LANDRISCINA C (1999) Changes in liver enzyme activity in the teleost Sparus aurata in response to cadmium. Ecotoxicol. Environ. Saf. 43 111-116.

VERNHET L, SEITE M-P, ALLAIN N, GUILLOUZO A and FARDEL $\mathrm{O}$ (2001) Arsenic induces expression of the multidrug resistanceassociated Protein 2 (MRP2) gene in primary rat and human hepatocytes. J. Pharmacol. Exp. Ther. 298 (1) 234-239.

WRCA (2003) The Impact of Introducing Treated Water on Aspects of Community Health in a Rural Community in Kwazulu-Natal. 
WRCA Report No 925/1/03. http://www.fwr.org/wrcsa/925103.htm (accessed on 5 September 2006)

XU C, LI CY and KONG AN (2005) Induction of phase I, II and III drug metabolism/transport by xenobiotics. Arch. Pharm. Res. 28 (3) $249-268$.
ZWINGMANN C, LEIBFRITZ D and HAZELL AS (2003) Energy metabolism in astrocytes and neurons treated with manganese: Relation among cell specific energy failure, glucose metabolism and intercellular trafficking using multinuclear NMR-spectroscopic analysis. J. Cereb. Blood Flow. Metab. 23 (6) 756-771. 